Ding, Y,; Kuhlbusch, T.A.J.; Van Tongeren, M.; Sanchez Jiménez, A.; Tuinman, I.; Chen, R.; Larraza Alvarez, I. et al. Airborne engineered nanomaterials in the workplace : a review of release and worker exposure during nanomaterial production and handling processes. Journal of Hazardous Materials 322(Part A): 17-28, 2016.

\begin{tabular}{|l|l|}
\hline Postprint version & Final draft post-refereeing \\
\hline Journal website & $\underline{\text { http://www.sciencedirect.com/science/journal/03043894/ }}$ \\
\hline Pubmed link & $\underline{\text { http://www.ncbi.nlm.nih.gov/pubmed/27181990 }}$ \\
\hline DOI & $\underline{\underline{10.1016 / j . j h a z m a t .2016 .04 .075}}$ \\
\hline
\end{tabular}




\title{
Airborne Engineered Nanomaterials in the Workplace-a Review of Release and Worker Exposure during Nanomaterial Production and Handling Processes
}

\author{
Yaobo Ding ${ }^{1}$, Thomas A.J. Kuhlbusch ${ }^{2,3}$, Martie Van Tongeren ${ }^{4}$, Araceli Sánchez Jiménez ${ }^{4}$, Ilse \\ Tuinman $^{5}$, Rui Chen ${ }^{6}$, Iñigo Larraza Alvarez ${ }^{7}$, Urszula Mikolajczyk ${ }^{8}$, Carmen Nickel $^{2}$, Jessica Meyer ${ }^{2}$, \\ Heinz Kaminski ${ }^{2}$, Wendel Wohlleben ${ }^{9}$, Burkhard Stahlmecke ${ }^{2}$, Simon Clavaguera ${ }^{10}$, Michael Riediker ${ }^{1,11}$ \\ ${ }^{1}$ Institute for Work and Health (IST), Universities of Lausanne and Geneva, Route de la Corniche 2, 1066, \\ Epalinges, Switzerland \\ ${ }^{2}$ Institute of Energy and Environmental Technology (IUTA), Air Quality \& Sustainable Nanotechnology \\ Unit, Bliersheimer Straße 58-60, 47229, Duisburg, Germany $3^{3}$ Centre for Nanointegration (CENIDE), \\ University Duisburg-Essen, Duisburg, Germany \\ ${ }^{4}$ Centre for Human Exposure Science, Institute of Occupational Medicine (IOM), Research Avenue North, \\ Edinburgh EH14 4AP, United Kingdom \\ ${ }^{5}$ TNO, Lange Kleiweg 137, Rijswijk, The Netherlands \\ ${ }^{6}$ CAS Key Lab for Biomedical Effects of Nanomaterials and Nanosafety, National Center for Nanoscience \\ and Technology of China, Beijing 100190, P. R. China \\ ${ }^{7}$ ACCIONA Infrastructure, Materials Area, Innovation Division, C/Valportillo II 8, 28108, Alcobendas, \\ Spain \\ ${ }^{8}$ Nofer Institute of Occupational Medicine, Lodz, Poland \\ ${ }^{9}$ Dept. Material Physics, BASF SE, Advanced Materials Research, Ludwigshafen, Germany \\ ${ }^{10}$ NanoSafety Platform, Commissariat à l'Energie Atomique et aux Energies Alternatives (CEA), Univ. \\ Grenoble Alpes, Grenoble, 38054, France \\ ${ }^{11}$ SAFENANO, IOM Singapore, 30 Raffles Place \#17-00 Chevron House, Singapore, 048622, Singapore \\ Corresponding author: Michael Riediker; Tel. +65 6809 6249; \\ E-mail address: Michael.Riediker@alumni.ethz.ch
}

\begin{abstract}
For exposure and risk assessment in occupational settings involving engineered nanomaterials (ENMs), it is important to understand the mechanisms of release and how they are influenced by the ENM, the matrix material, and process characteristics. This review summarizes studies providing ENM release information in occupational settings, during different industrial activities and using various nanomaterials. It also assesses the contextual information - such as the amounts of materials handled, protective measures, and measurement strategies - to understand which release scenarios can result in exposure. High-energy processes such as synthesis, spraying, and machining were associated with the release of large numbers of predominantly small-sized particles. Low-energy processes, including laboratory handling, cleaning, and industrial bagging activities, usually resulted in slight or moderate releases of relatively large agglomerates. The present analysis suggests that process-based release potential can be ranked, thus helping to prioritize release assessments, which is useful for tiered exposure assessment approaches and for guiding the implementation of workplace safety strategies. The contextual information provided in the literature was often insufficient to directly link release to exposure. The studies that did allow an analysis suggested that significant worker exposure might mainly occur when engineering safeguards and personal protection strategies were not carried out as recommended.
\end{abstract}

Keywords: nanoparticles, emission, grouping, occupational exposure, risk assessment

Journal of Hazardous Materials 05/2016; DOI: 10.1016/j.jhazmat.2016.04.075 


\section{Introduction}

Engineered nanomaterials (ENMs) possess different physical and chemical properties than their bulk counterparts and, because of this, are used in manufacturing processes for a variety of applications [1]. However, during their production and use, ENMs may be released into the workplace, resulting in workers' exposure. Understanding release is important for accurately describing the exposure scenarios that are helpful for risk assessment and management [2], which are required under regulatory schemes such as REACH in the EU [3].

Release can be referred to as the detachment of nanomaterials from a body of powder, a suspension, or a solid matrix [4]. This can be expressed as a rate describing the amount of material released per unit of time. In workplaces, the release of ENMs can occur throughout their entire lifecycle - manufacturing, use, and recycling. Release mechanisms depend on the physical state of the material (powder, suspension, or solid) and the amount of energy introduced by specific processes. For powders, environmental humidity and the moisture content of the raw powder have a significant influence on the release level, as suggested by dustiness studies [5]. Liquid suspensions containing ENMs can release nanoparticles from the solution's surface when external energies are applied, such as stirring [6], sonication [6, 7], centrifuging, [8] or spraying [6,9]. The release rate from liquids depends on factors such as the ENM concentration and its solubility in the solution. Release from solid matrices is mainly caused by the mechanical treatment of nanocomposites, including drilling, sawing, and sanding [10-12]. Parameters such as the ENM's concentration and distribution within the composite matrix and the process conditions (e.g., treatment type, temperature, or relative humidity), as well as ageing processes such as weathering [13], play important roles in release rates and forms (e.g, agglomerate, individual particle, mixture of ENM and matrix material).

To prevent or reduce ENM releases, it is important to understand the determinants of release related to nanomaterials, the matrix in which they are embedded (if at all), and the process and/or activity involved. Tsai et al. [14] reported that handling $100 \mathrm{~g}$ of nano-alumina powder resulted in a much higher released particle concentration than handling $15 \mathrm{~g}$. High-energy processes, such as pouring, generate more particles than less vigorous processes, such as transferring. Johnson et al. [7] found that the sonication of functionalized multi-walled carbon nanotubes (MWCNTs) in reconstituted water containing natural organic matter resulted in particle concentrations three times higher than sonicating raw MWCNTs in the same medium.

Material that was detached (i.e., released) from a powder body, a liquid, or a solid matrix can be emitted depending on the process specifications and on-site control measures in place. Figure 1 depicts a typical occupational setting from which ENMs could be released, emitted, and transported, resulting in exposure to workers. If the release rate cannot be directly calculated from a predefined release mechanism, it may still be possible to estimate it from the information on source concentrations, near-field volume flow rates, and the release start point and duration. Some of the released particles might be captured by engineering controls (e.g., ventilation or enclosure); the escaped portion, which subsequently disperses into working environments, is called emission. Transmission describes the process during which emitted aerosols are transported to the immediate receptors, which then results in exposure.

Amongst the metrics used to characterize the release of nanomaterials, particle number and mass concentration are the two most widely used parameters for airborne ENMs in occupational settings [15], possibly due to the availability of sampling equipment and mature sampling procedures. Such data allow the creation of rankings for the release potential of common industrial processes and the study of how release is influenced by factors such as the quantity of material needed, how it is treated, the energy levels associated, and variable human factors. 




Figure 1. Diagram representing various elements and processes in an occupational exposure scenario

In addition to the characterization of the ENMs released, such as that provided by ISO [16], a comprehensive exposure assessment should also include the necessary contextual information. Clark et al. [2] pointed out that the level of relevant detailed information in the existing literature on exposure is often insufficient for an in-depth understanding of the situation being studied. Parameters such as ventilation type, the personal protective equipment (PPE) used, sampling locations, frequency and duration of worker activity, and personal sampling data are often not fully described. This information is critical to transform upstream release data into downstream exposure estimates. Only sufficiently detailed meta-data will allow the development of exposure scenarios that are valid for risk assessment purposes and that can be used for establishing health and safety strategies.

This paper reviews the information on ENM release and exposure in the scientific literature and assesses how they inform us about the related human exposure in workplaces. The availability of the contextual information needed for exposure and risk assessment was assessed to identify potential gaps in data collection and reporting. The characteristics of released ENMs-including number concentration, mean size, and morphology—were compared for different processes involved in order to facilitate a general grouping and ranking of release potential. Measurement strategies, such as the equipment types and sampling locations used in field studies, were evaluated to give a better understanding of release and exposure data. Furthermore, production capacities and amounts handled were compared across different activities and materials in order to identify processes with a possibility of high occupational exposure. Finally, the types and efficiencies of engineering controls were summarized in order to describe the overall level of protection for workers in nanotechnology workplaces.

\section{Method}

We conducted a systematic review of scientific publications describing real-world measurements of airborne ENM release and exposure in industry and research laboratories. The goal was to cover a wide range of relevant studies on this topic and describe the current information and knowledge about ENM release in workplaces. 
The studies examined were collected from multiple literature sources. As a first step, 26 publications were identified in the NANEX database. The NANEX project's goal was to build a comprehensive library of occupational exposure scenarios for ENMs throughout their entire lifecycle [17]; it includes scientific literature and large surveys which generally contain descriptions of the material, the processes and activities, release levels of airborne nanoparticles, and subsequent exposure estimates under specific environments. The literature covered scenarios related to the production of ENMs at a research-scale, as well as in industrial settings and downstream uses. The information available was a very good fit with the context of our review. Thus, the list of literature in the NANEX database was used to target relevant publications. Another identified comprehensive library on types of nanomaterials and nanoobjects used in various industrial processes was the R-Nano platform [18].

In a second step, we searched public online databases such as PUBMED and ScienceDirect. Keywords were chosen by analyzing the frequency with which they appeared in the titles of the selected NANEX publications. The most common words were release, exposure, workplace(s), airborne, nanoparticle(s), and characterizations. Combinations of these terms were then used in the searches. The names of specific materials were also used-such as titanium dioxide ( $\left.\mathrm{TiO}_{2}\right)$, carbon nanotubes (CNTS), and silver ( $\mathrm{Ag}$ ) - to ensure the completeness of the search. Articles were screened and then retained if they fulfilled the following three conditions: 1) they at least partly addressed release associated with airborne ENMs; 2) their measurements were conducted in occupational settings (industrial or research facilities); 3) they comprised quantitative descriptions of ENM release scenarios, such as particle number or mass concentrations. All the collected articles were written in English..

Additional potentially relevant publications were identified using the related citations function, as suggested by the online databases when searching for specific items. This is usually a very efficient method for quickly identifying target articles.

The present review specifically assessed the release characteristics of different industrial and laboratory processes. This involved evaluating the completeness of the information in activity descriptions, especially the process parameters that influence release scenarios. It also looked at whether the information collected would allow a calculation of actual release rates, such as the sampling distance to source and ventilation rates. Finally, the review considered whether information on a material's properties and the quantities treated in a specific process were sufficiently detailed to inform us about the characteristics of released particles, including concentration and size distribution.

To ensure that the information extraction process was carried out in a systematic and repeatable manner, one person first coded all the information. Subsets of reference articles were then coded by several co-authors with the same coding rules. This control coding resulted in an almost perfect match.

\section{Linking release to exposure: literature analysis}

\subsection{Literature identified in the review}

The articles collected and reviewed are summarized in Table S1 (Supplementary information, SI) by year, type (research or industry), material and activity. The years of publication range from 2004 to 2016. This represents the period when nanotechnologies were developing rapidly, and there was increased reporting on issues regarding exposure to ENMs. Most of the studies focused on exposure assessments reporting contaminant concentrations in workplace air. Twenty-five percent of publications investigated laboratory activities, 63\% looked at industrial processes, and the remaining $12 \%$ investigated both. A large part of this literature focused on exposure to carbonaceous materials, followed by various metals and metal oxides. In some cases, the information provided failed to indicate the material type. Activity types included synthesis, processing, handling, cleaning, machining, and others, during different phases of ENM lifecycles.

\subsection{Information availability}


We first assessed which of the elements considered as important for linking release to exposure-when developing exposure scenarios-were available in the articles selected. Figure 2 shows how available each of these elements of information was in the publications reviewed. It is divided into three sub-groups: contextual information, measurement strategy, and characterizations. Two different periods of publishing year were analyzed to assess whether the general situation as well as the information availability improved in recent years. The complete dataset can be found in the supplemental information (Table S2).

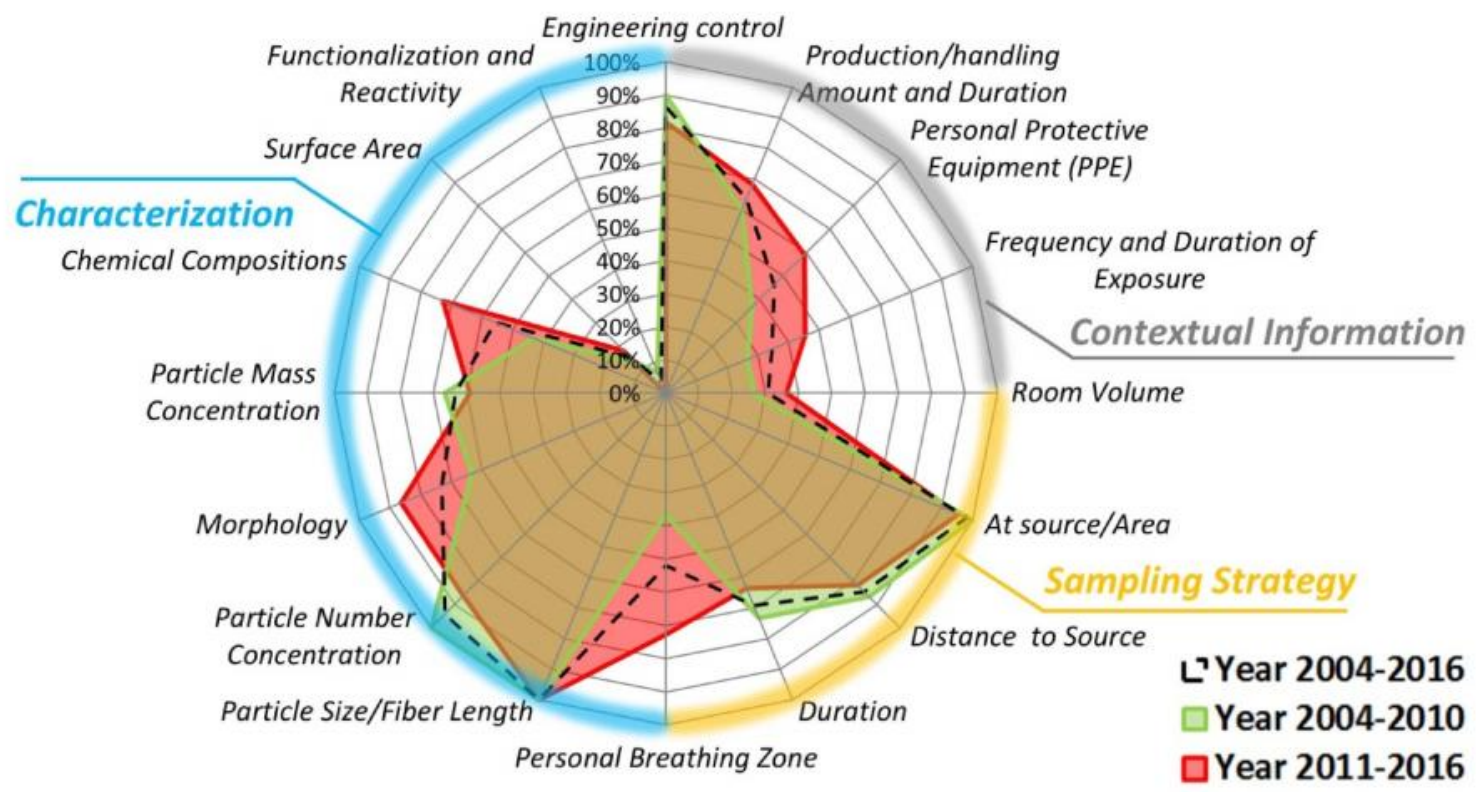

Figure 2. Summary of the percentage of articles providing essential elements of release- and exposure-relevant information: average of all publications as well as separated by early (2004-2010) and recent (2010-2016) publications.

In the full time period analyzed (2004-2016), types of engineering controls were frequently provided as contextual information. About two-thirds of the articles described the quantity of material being treated, and about a half indicated the PPE used. In contrast, only about a third of the papers specified the volume of the room involved and the frequency and duration of the activity (thus when there is potential for exposure). However, recently published literature (2011-2016) showed better data availability, especially regarding PPE, level of contact and room volume.

As part of measurement strategies, at-source and area measurements were normally conducted for release and background characterizations. The sampling duration and distance to the source were usually given in the description of measurement methods. However, personal breathing-zone data were only available in about half of the publications. Again, the recent articles showed a large improvement in reporting personal sampling data, doubling the rate from $36 \%$ (2004-2010) to $73 \%$ (2011-2016).

For particle characterizations, most studies provided number-based concentration and size distributions by using direct reading instruments $(>90 \%)$. In contrast, particle mass concentration and morphology analysis were less frequently reported (60-70\%). About half of the literature performed analyses of the chemical composition of airborne ENM samples. Other physical and chemical properties - such as surface area, surface reactivity, and functionality-were less often or rarely characterized. Compared to earlier publications, the recent ones seemed to report more often on particle morphology (86\%) and elemental composition (73\%).

Due to readily available equipment and mature, established procedures, the characterization of particle number and mass concentrations were relatively easy to carry out. For other metrics, such as surface area and coating type, 
collecting suitable data might have been difficult due to a lack of reliable equipment for on-line or off-line analysis of these properties. The data suggests a remarkable improvement over the last five years on reporting of exposurerelevant contextual information and personal exposure data. This change may be attributed to improved access to advanced techniques, as well as to researchers' growing awareness of the importance of elements for conducting proper nanomaterial worker exposure assessment. Several calls among exposure assessment scientists for harmonization of exposure data collection, analysis, reporting as well as storage strategies have been made (Brouwer 2011, Clark 2012), to meet the needs for building up exposure scenarios, modeling and meta-analysis in risk assessment. 3.3 Activities and released materials

The industrial processes and laboratory activities identified were investigated for their potential to release airborne ENMs. They were grouped by the nature of the processes and activities and the types of particles identified in them. Collecting and sorting materials during production were the most commonly described activities, followed by physical and chemical synthesis processes. Other activities include ordinary handling of ENMs such as weighing, mixing and transferring, as well as cleaning and maintenance. Machining and mechanical processing of ENMs or ENMs-containing products (e.g., nanocomposites) as well as spraying operations also have high potentials to generate airborne dusts. The most frequently assessed groups of processes are further described in Table 1. Identified ENM types categorised by activity type are shown in table 2. . Metals and their oxides, such as silver, titanium dioxide, silica, alumina, ceria and iron oxide, were commonly assessed. Carbonaceous materials, including CNTs (MWCNTs and SWCNTs), carbon black, carbon nanofibers and fullerenes were also among the most frequently investigated materials. A series of studies also described types of unexpectedly released particles, such as plastic materials generated from hot-sealing collection bags during packaging [19] and nanoscale particles emitted by forklifts in warehouses [6, 20-22].

\begin{tabular}{|c|c|}
\hline Activity type & Examples from the literature review \\
\hline $\begin{array}{l}\text { Collecting } \\
\text { and sorting } \\
\text { during ENM } \\
\text { productions }\end{array}$ & $\begin{array}{l}\text { Collecting end-product materials from chemical synthesis [23]; batch collection by industrial } \\
\text { cyclone [24]; emptying and tipping powder materials from bucket to bucket [25]; scooping spilt } \\
\text { materials off a table [25]; opening a furnace and transferring materials to vials [6]; manually } \\
\text { loading and unloading trays [6]; dumping materials into a mixing tank [6]; detaching and removing } \\
\text { CNTs from growth substrate using a razor blade [26]; sieving powders with a vibratory sieve } \\
\text { shaker [27, 28] }\end{array}$ \\
\hline $\begin{array}{l}\text { Physical } \\
\& \quad \text { chemical } \\
\text { synthesis }\end{array}$ & $\begin{array}{l}\text { Gas-phase production of metal-based nanoparticles [29]; flame spray pyrolysis technique (FSP) } \\
{[30,31] \text {; induced coupled plasma with electric atomizer [32, 33]; reaction collection [23]; electric }} \\
\text { arc reaction [34]; hot-wall reaction[19]; combustion reaction [35]; chemical vapor deposition } \\
\text { (CVD) [26, 36-39]; water-assisted CVD [40] }\end{array}$ \\
\hline $\begin{array}{l}\text { Weighing } \\
\text { \& mixing }\end{array}$ & $\begin{array}{l}\text { Handling nanopowders in an exhaust hood [31]; transferring from storage container to a balance } \\
\text { [7]; weighing inside a fume hood[41]; mixing nanofibers with solvents [41]. mixing CNTs } \\
\text { powders with polymer melt in an extrusion process [42] or during injection moulding [43, 44] }\end{array}$ \\
\hline $\begin{array}{l}\text { Machining } \\
\& \text { abrasion }\end{array}$ & $\begin{array}{l}\text { Wet-sawing nanocomposites [6]; cutting and winding coated substrate during electrospinning } \\
\text { deposition onto a cellulose substrate [6]; band-sawing nanocomposites [45]; cutting composites } \\
\text { using a water-cooled, dust-suppressed table saw [41]; chopping extrude composites [41]; fettling } \\
\text { (removal of excess molding materials by sawing) [46]. dry cutting of reacted graphite deposit } \\
\text { with a band saw [47]; lathe machining of graphite rods for the reactor [47] }\end{array}$ \\
\hline $\begin{array}{l}\text { Cleaning } \\
\& \\
\text { maintenance }\end{array}$ & $\begin{array}{l}\text { Cleaning a pyrolysis system [31]; cleaning an enclosure after laser ablation synthesis [25]; vacuum } \\
\text { cleaning an enclosure in High-Pressure CO Conversion [25]; vacuum cleaning after creating and } \\
\text { spray-drying slurries [6]; reactor cleanout [6]; cleaning/brushing down a plasma torch in a radio- } \\
\text { frequency induction plasma reactor [6]; cleaning-up spilled materials from dumping operations } \\
\text { [48]; Purge and prime slurry delivery system, load new slurry from bulk into day tanks [49] }\end{array}$ \\
\hline
\end{tabular}


Others Spraying and filtration of CNT solutions [37]; spraying solution onto a bulk absorbent [6]; changing a spray dryer drum [6]; spraying a suspension [9]; flame-spraying for surface coating and modification [50]; sonicating materials with different surface coatings in a hood [6]; sonication in an unventilated enclosure [7]; pelletizing and bagging products in a warehouse [51]; purification and functionalization[47] integrating MWCNT powder in coatings, dispersions, and plastics [52]

Table 1. Types of activities most often described as causing airborne ENM release, together with typical examples.

\begin{tabular}{ll}
\hline Activity type & Material type \\
\hline $\begin{array}{l}\text { Collection, } \\
\text { sorting \& }\end{array}$ & Metal/metal oxides: $\mathrm{TiO}_{2}[6,24,32], \mathrm{SiO}_{2}$ [53], $\mathrm{Al}_{2} \mathrm{O}_{3}$ [53], $\mathrm{CeO}_{2}$ [53], iron oxides [6], $\mathrm{Mn}[6]$, \\
processing & Carbonaceous: carbon black [23], CNT [26], SWCNT [25, 40, 55], MWCNT [6, 28, 37, 47], \\
(including & carbon nanofibers (CNFs) [6, 48], carbon nanopearls [6], nano diamond [27], carbon \\
sieving) & nanodiscs/carbon nanocones [28], nanoscale graphene platelets [56].
\end{tabular}

Physical \& chemical synthesis
Metal/metal oxides: $\mathrm{TiO}_{2}$ [31, 32, 35, 57], $\mathrm{Al}_{2} \mathrm{O}_{3}$ [35, 57], $\mathrm{Ag}_{2} \mathrm{O}$ [58], $\mathrm{MgO} / \mathrm{Y}_{2} \mathrm{O}_{3} / \mathrm{CaO} / \mathrm{FeO}$ [35], $\mathrm{BiPO}_{4} / \mathrm{Bi}_{2} \mathrm{O}_{3} / \mathrm{NaCl} / \mathrm{CaSO}_{4} / \mathrm{ZnO} / \mathrm{ZrO}_{2} / \mathrm{WO} / \mathrm{Ta}_{2} \mathrm{O}_{5} / \mathrm{Pt} / \mathrm{Ba}$ [57], lithium titanate [59], $\mathrm{Ag}$ [32, 33], Si [19], metal-based nanoparticles [29];

Carbonaceous: CNT [26], MWCNT [28, 36-38, 47, 52], SWCNT [38, 40], CNFs [39], Nanofibers [31], nanostructured materials [31], carbon black [23], carbonaceous nanomaterials [34], nanoscale graphene platelets [56].

Weighing, transferring \& mixing*

Metal/metal oxides: $\mathrm{TiO}_{2}$ [6, 24, 35], $\mathrm{Al}_{2} \mathrm{O}_{3}$ [14, 35], $\mathrm{CuO}$ [6], $\mathrm{SiO}_{2}$ [21], $\mathrm{ZnO}$ [9],

$\mathrm{MgO} / \mathrm{Y}_{2} \mathrm{O}_{3} / \mathrm{CaO} / \mathrm{FeO}$ [35], $\mathrm{CeO} 2$ [58], $\mathrm{Ag}[6,14], \mathrm{Si}$ [19], indium tin oxide [9];

Carbonaceous: MWCNT [6, 7, 28, 36, 42, 52], CNTs [43, 44], carbon black [7], nanofibers

[31], carbon nanofibers [6, 41], fullerenes [6, 7], carbon nanodiscs/carbon nanocones [28];

Others: ceramic powders [31].

\begin{tabular}{|c|c|}
\hline $\begin{array}{l}\text { Machining \& } \\
\text { abrasion }\end{array}$ & CNFs [6, 41], Nylon 6 nanofiber [6], alumina fiber [60], MWCNT [60], carbon fibers [60]. \\
\hline $\begin{array}{l}\text { Cleaning \& } \\
\text { maintenance }\end{array}$ & $\begin{array}{l}\text { Metal/metal oxides: } \mathrm{TiO} 2 \text { [6], } \mathrm{Mn} \mathrm{[6],} \mathrm{Ag}[6], \mathrm{Co} \mathrm{[6],} \mathrm{Al}[6], \mathrm{Al}_{2} \mathrm{O}_{3} / \mathrm{SiO}_{2} / \mathrm{CeO}_{2} \text { [49], Meta } \\
\text { oxides ( } \mathrm{Ag}, \mathrm{Cu}, \mathrm{Co}, \mathrm{Ni}, \mathrm{Fe}, \mathrm{Mn} \text { ) [61], metal oxides ( } \mathrm{Mn}, \mathrm{Ag}, \mathrm{Co})[62] ; \\
\text { Carbonaceous: Nanofibers [31], SWCNT [25], fullerenes [63], carbon nanofibers [48], } \\
\text { Graphene [58], nanoscale graphene platelets [56]. }\end{array}$ \\
\hline Finishing** & $\begin{array}{l}\mathrm{CeO}_{2}[50], \mathrm{TiO}_{2}[6], \text { silica-iron nanomaterial [6], indium tin oxide [9], } \mathrm{ZnO}[9], \mathrm{SiO}_{2}[58] \\
\text { Carbon black }[23,51], \text { MWCNT [37]. }\end{array}$ \\
\hline $\begin{array}{l}\text { Packing and } \\
\text { bagging }\end{array}$ & $\begin{array}{l}\text { Carbon black [20, 21, 51, 58], Fullerenes [63], CNFs [48], MWCNT [28, 52], carbon } \\
\text { nanodiscs/nanocones [28]; } \mathrm{Si}[19], \mathrm{TiO}_{2}[22], \mathrm{SiO}_{2}[58], \mathrm{CaCO}_{3}[21] .\end{array}$ \\
\hline sonication & Fullerenes [6, 7], MWCNT [6, 7, 37], carbon black [7], $\mathrm{Ag}_{2} \mathrm{O}[58], \mathrm{CeO}_{2}[58]$. \\
\hline Testing & Cadmium-zinc/selenide quantum dots [6], Nylon 6 nanofiber [6]. \\
\hline Ball milling & MWCNT [36]. \\
\hline Feeding & Silver [64]. \\
\hline Recycling & $\mathrm{SiO}_{2} / \mathrm{Al}_{2} \mathrm{O}_{3} / \mathrm{CeO}_{2}[53] ; \mathrm{CNTs}[43,44]$. \\
\hline
\end{tabular}

Table 2 Classification of the types of ENMs identified from the literature by activity type 
When describing their release scenarios, most studies provided particle number and mass concentrations and at least some information about size distribution. Background measurements were frequently used as references. Table 3 presents the measurement results for airborne particle types, number concentrations, mean sizes and agglomeration state(additional information on particle mass concentrations are included in SI-Table S3). Number concentrations were reported in the size range 10 or $<10 \mathrm{~nm}-$ up to $>32 \mathrm{~m}$, usually obtained by scanning mobility particle sizers or optical particle counters, and often presented as continuous curves showing concentration evolution (changes) over time.. For non-continuous actions, such as handling [37] and cleaning [25], peak ranges were frequently used to document the release. Figure 4 ranks the near-source number concentrations and particle sizes by different production and handling activities.

Several studies investigated airborne ENM releases from laboratory sonication activities. The surface properties of sonicated materials seemed to strongly influence the release process. Sonication of raw MWCNTs in de-ionized water resulted in 2,200-2,800 particles $/ \mathrm{cm}^{3}$ below $1 \mu \mathrm{m}$ in the air above the water bath, whereas the same procedure done with functionalized MWCNTs (hydroxyl group addition) resulted in only about one third of this value [6]. However, another study showed a higher release of functionalized CNTs $\left(158 \# / \mathrm{cm}^{3}\right)$ in water containing natural organic matter, than normal CNTs $\left(56 \# / \mathrm{cm}^{3}\right)$ in the same media [7]. Furthermore, sonicating carbon black led to five times more particles being released than sonicating fullerenes in de-ionized water. Lee et al. reported that fine particles between 120-300 nm were released (at 2-3 times the background level) during the ultrasonic dispersion of MWCNTs in a fume hood, which was differentiated from fugitive particles $(<100 \mathrm{~nm})$ generated by other processes [37].

Cleaning was an activity often associated with the release of airborne particles in large sizes. Cleaning a pyrolysis system prior to operation resulted in a 10-fold increase in the airborne mass concentration, but no distinct change in particle numbers [31]. Vacuum cleaning following the chemical synthesis of single-walled carbon nanotubes (SWCNTs) led to the release of very large microsized agglomerates into the air [65]. In another case, where vacuum cleaners without HEPA filters were used to clean up after the creation of titanium slurries during spray drying, 10to 50-fold increases in number concentrations were measured for particles in the 300-1000 nm range [6]. In a cleanout activity following the gas-phase condensation manufacture of silver nanoparticles, five times more particles were measured in the 500-1000 nm range [6]. Similarly, cleaning the filter chamber and cyclone of a radiofrequency induction plasma reactor for aluminum production was associated with $15,580 \mathrm{p} / \mathrm{cm}^{3}$ of air, with more than ten times more particles in the 300-1000 nm range [6]. Furthermore, sweeping up spilled materials from a dumping operation also slightly increased $\left(<0.2 \mathrm{mg} / \mathrm{m}^{3}\right)$ the mass concentration of respirable particles [66].

Industrial packaging and bagging activities often released large ENM particle agglomerates into the air. Kuhlbusch et al. reported a four- to eight-fold increase of PM10 mass concentrations, mostly for particles larger than $400 \mathrm{~nm}$, during the bagging of carbon black [20]. In another study investigating the same material, the number concentration was elevated for particles > $100 \mathrm{~nm}$ [21]. During the removal of fullerenes from a storage tank, airborne particles larger than $1000 \mathrm{~nm}$ were identified [63]: the fullerenes existed mainly as aggregates and agglomerates in the air. $\mathrm{TiO}_{2}$ aerosols were found to be released at diameters up to $6.0 \mathrm{~m}$ during packing [22]. Bagging carbon nanofiber end-products released 230-3,130 carbon nanofiber $\mathrm{p} / \mathrm{cm}^{3}$ of air [66]. Area sampling resulted in a $0.5-1.1 \mathrm{mg} / \mathrm{m}^{3}$ mass concentration, mainly made up of carbon nanofibers.

Weighing and mixing processes usually resulted in only minor or moderate increases in airborne ENM particle concentrations. No significant releases were recorded during the handling of synthetic ceramic nanopowders [31], transferring carbonaceous materials [7], or the laboratory handling of metal oxides [9]. During the weighing and transfer of different nanomaterials, release scenarios varied [7]. Handling raw MWCNTs and fullerenes generated much higher particle counts than the background, whereas treating functionalized MWCNTs and carbon black generated no significant release. In contrast, handling nanofibers generated particle concentrations up to 15,000 $\mathrm{p} / \mathrm{cm}^{3}$, which was six to twenty times above the background level [31]. 
Physical and chemical synthesis were associated with potential releases of airborne ENM particles in smaller sizes. No significant release was observed in comparison to background levels during the experimental-scale production of nanofibers [31], pyrolysis production of $\mathrm{TiO}_{2}$ [31], CVD growth of CNTs [26] and MWCNTs [36], and synthesis of Ag by mixing sodium citrate with silver nitrate [67]. In contrast, one study showed significant at-source releases from the CVD production of CNTs at sizes below $100 \mathrm{~nm}$ (probably carbonaceous by-products) and from 7-200 nm [68]; using higher injection temperatures released more particles of reduced diameters (from 20-200 to 7-90 nm). Synthesis of $\mathrm{TiO}_{2}$ generated noticeable particle concentrations with a bimodal distribution (<30 nm and 70-100 nm) [67], whereas induced-coupled-plasma production of Ag resulted in significant releases in the 20-30 nm range. Flame synthesis of metal oxides registered particle emissions in the 112-185 nm and 24-29 nm ranges, depending on the materials produced. Process parameters, such as filter-to-flame distance, precursor-to-oxygen ratio, and flame numbers appeared to influence the release scenarios [30]. For industrial processes, the reaction-collection of carbon black and the electric arc reaction of other carbonaceous materials mostly released particles in the 10-100 nm range $[23,34]$. Gas-phase production of metal-based nanoparticles resulted in submicron particle releases at modes in the 160-200 nm range [29]. In vapor grown synthesis of carbon nanofibers, the nanofibers were found to be the dominant source of elementary carbon, but iron-rich soot-like particles at $20 \mathrm{~nm}$ were also identified [39]. Combustion reaction processes were shown to emit particles smaller than $300 \mathrm{~nm}$ [35]. In all these studies, the mass concentrations measured were often low, which indicates that mainly small particles were released.

Machining and abrasion of nanocomposites were often shown to release matrix materials with embedded ENM fillers. Furthermore, the release mechanisms varied by process type, parameters, and matrix as well as the filler materials. Wet-sawing of carbon nanofiber composites showed high particle release in terms of mass but not in numbers [6, 69]. A dry process was associated with a much lower particle emission than a wet process using the same materials [60]. In wet treatments, it is likely that the detected nanoscale particles were primarily water droplets. Comparing different materials, alumina fiber/CNT composites showed the least particle release, whereas alumina composites resulted in elevated particle generation. The thickness of the composite layer also affected particle release. No primary CNT structures or bundles were identified in the released particles.

Spraying process mostly led to high levels of airborne particles of very small sizes. In flame-spray processes used for coating and the surface modification of materials, the highest releases $\left(160,000-210,000 \mathrm{p} / \mathrm{cm}^{3}\right)$ were seen during the active phases of the process (flame on, precursor on) [50]. The particle size distribution showed multiple modes in the 10-454 $\mathrm{nm}$ range. Changing spray dryer drum also released high airborne concentrations of spray materials [6]. One extreme case reported concentrations up to $18,000,000 \mathrm{p} / \mathrm{cm}^{3}$ at $54 \mathrm{~nm}$ in the personal breathing zone [9]. Spraying suspensions and pyro silanization registered high releases in the 55-99 $\mathrm{nm}$ range.

Other sources of nanosized particles were reported for all types of activities. Forklift trucks were a common source of ultrafine particles $(<100 \mathrm{~nm})$ in activities such as warehouse bagging and packaging of carbonaceous materials [20, 21, 70] and $\mathrm{TiO}_{2}$ pigment [22]. Vacuum cleaners were also found to release nanoscale particles [63], especially when no HEPA filter was installed [6]. Other combustion sources, such as butane gas heaters [20], gas-fired radiant heaters [66], and hot-sealing plastic bags [19], were also found to release very small particles. Additionally, a rotarytype oil vacuum pump was identified as a source of $300 \mathrm{~nm}$ particles [36]. Polymer fume condensate can release nanoparticles during nanocomposite manufacturing by extrusion processes [42, 44, 71]. The studies were able to distinguish these secondary releases of nanoscale particles by comparing the aerosol profiles (size and concentration) obtained with and without their potential sources. Although toxicological studies focus mostly on ENMs, it might be of equal importance to characterize the accidentally released nanoparticles in workplaces. 



Figure 4. Near-source airborne ENM particle concentrations (left) and sizes (right) (modal size or estimation from transmission electron microscopy analysis) in workplaces, ranked by production and handling activities (data source: table 3). Results are shown for number concentration and for size. Activity type: (1)Cleaning; (2)Packing and bagging; (3)Sonication; (4)Weighing, mixing and transferring; (5)Machining; (6)Production; (7)Spraying.

In most of the cases, released airborne ENMs were agglomerates or aggregates, often resulting in complex particle morphologies, such as loose, porous clusters of metal oxides particles [6], densely packed Ag particles [72], entangled CNFs [31, 69], chain-like structures of CNTs [68] or in certain cases combining with other background particulate matters [42, 47]. Only one study reported individual Ag vapor condensate particles [73]. This finding is in line with the conlusions on released particle morphology from previous reviews on ENMs exposure at workplaces $[15,74,75]$.

The results from ENM release scenarios seemed to be largely determined by process energy. High energy processes such as synthesis, spraying, and machining released large amounts of airborne ENM particles in the nanometer range. Low energy processes including laboratory handling, packing and bagging on production lines, and cleaning usually resulted in slight or moderate increases in ENM particle concentrations in the air. The particles released by these processes were often large agglomerates with sizes up to several micrometers. Furthermore, release mechanisms were found to be influenced by process parameters, material properties, and environmental conditions. These included, for example, material quantities, ambient humidity [14], and surface functionality [6] during material handling. Smaller quantities, hydrophilic surfaces, and higher humidity seemed to reduce particle concentrations. During sonication, the solubility of materials in the liquid media played an important role [7]. More soluble materials had lower chances of escaping from the solution and becoming airborne. During physical and chemical synthesis, reactor setup and process temperature both affected release levels [30]. Dynamic reaction processes and poor filtration resulted in higher ENM particle emissions. During the mechanical processing of nanocomposites, the filler type, its distribution in the matrix, and the treatment conditions (dry or wet) modified the release scenario [6, 60, 69]. Lower filler contents and humid atmospheres helped reduce particle emissions and personal exposure during processing. 


\begin{tabular}{|c|c|c|c|c|c|c|c|}
\hline & Ref & Material & $\begin{array}{l}\text { Background, } \\
\text { p/cm3 }\end{array}$ & $\begin{array}{l}\text { During activity, } \\
\text { p/cm3 }\end{array}$ & $\begin{array}{l}\text { Sampling size } \\
\text { range, } \mathrm{nm}\end{array}$ & Mean size** & A.* \\
\hline \multirow{13}{*}{ 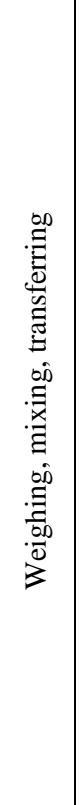 } & {$[6]$} & $\begin{array}{l}\text { Composite } \\
\text { materials }\end{array}$ & $700-19,500$ & 4,000 & $10-1000$ & $0.5 \times 3 \mu \mathrm{m}$ & A. \\
\hline & {$[6]$} & MWCNT & 14,700 & $57,000-157,800$ & $10-1000$ & $0.5-1 \mu \mathrm{m}$ & A. \\
\hline & {$[27]$} & Nanodiamonds & $4,600 \pm 2,900$ & $6,000-20,000$ & $\begin{array}{c}10-1000 \\
14-573\end{array}$ & $0.5 \mu \mathrm{m}$ & A. \\
\hline & [7] & $\mathrm{C}_{60}$ fullerenes & 14,922 & 72,085 & $10-1000$ & $\sim 300 \mathrm{~nm}$ & A. \\
\hline & [7] & MWCNT & 14,922 & $18,782-177,155$ & $10-1000$ & $\sim 500 \mathrm{~nm}$ & A. \\
\hline & [41] & $\mathrm{CNF}$ & $10,000-20,000$ & $10,000-20,000$ & $10-1000$ & $\sim 500 \mathrm{~nm}$ & A. \\
\hline & {$[14]$} & Alumina, $\mathrm{Ag}$ & BG subtracted & $\begin{array}{c}1,575-13,260(\mathrm{PBZ}) \\
1,131-22,932\end{array}$ & $5.6-560$ & $\begin{array}{c}50-100 \mathrm{~nm}, 200 \\
\mathrm{~nm}\end{array}$ & A. \\
\hline & {$[31]$} & Nanofibers & 700 & $\begin{array}{l}15,000 \text { (peaks), } 6 \text { to } \\
20 \text { time increase }\end{array}$ & $5 \mathrm{~nm}$ to $>32 \mu \mathrm{m}$ & $10 \times 1000 \mathrm{~nm}$ & A. \\
\hline & [71] & $\mathrm{CNT}$ & 1,000 & 4,400 & $5-1000$ & N/A & N/A \\
\hline & [27] & Nanodiamonds & $4,600 \pm 2,900$ & $6,000-20,000$ & $14 \mathrm{~nm}-31 \mu \mathrm{m}$ & $>500 \mathrm{~nm}$ & N/A \\
\hline & {$[58]$} & $\mathrm{SiO}_{2}$ & $13,603-17,679$ & $54,573-83,459$ & $5-500$ & $0.1-100 \mu \mathrm{m}$ & A. \\
\hline & {$[58]$} & $\mathrm{Al}_{2} \mathrm{O}_{3}$ & $8,664-10,641$ & $88,699-134,403$ & $5-500$ & $0.05-10 \mu \mathrm{m}$ & A. \\
\hline & {$[58]$} & $\mathrm{SiO}_{2}$ & $13,357-85,272$ & $72,096-100,856$ & $10-300$ & $0.5-25 \mu \mathrm{m}$ & A./I. \\
\hline \multirow{3}{*}{ 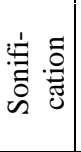 } & [7] & MWCNT, CB & $724-1,250$ & $1,450-3,500$ & $10-1000$ & $300-500 \mathrm{~nm}$ & A. \\
\hline & [37] & MWCNT & $2,000-3,000$ & $5,276-6,399$ & $5 / 14-500$ & $120-300 \mathrm{~nm}$ & N/A \\
\hline & {$[6]$} & C60, MWCNT & N/A & $730,2200-2800$ & $10-1000$ & $\sim 200 \mathrm{~nm}$ & A. \\
\hline \multirow{5}{*}{ 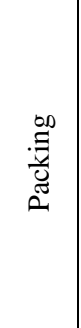 } & {$[20]$} & $\mathrm{CB}$ & N/A & $1,000-5,000$ & $200-700$ & $\begin{array}{c}>0.4(1 \mathrm{um} / 8 \mu \mathrm{m} \\
\text { modes })\end{array}$ & A. \\
\hline & [66] & $\mathrm{CNF}$ & N/A & $230-3130$ & $5 \mathrm{~nm}-10 \mu \mathrm{m}$ & $200-250 \mathrm{~nm}$ & N/A \\
\hline & {$[21]$} & $\mathrm{CaCO}_{3}$ & 4,000 & $10,000-50,000$ & $14-673$ & $\begin{array}{c}200-300 \mathrm{~nm}, \\
5.2 \mu \mathrm{m}\end{array}$ & A. \\
\hline & {$[22]$} & $\mathrm{TiO}_{2}$ & N/A & N/A & $56 \mathrm{~nm}-18 \mu \mathrm{m}$ & $5.52-7.25 \mu \mathrm{m}$ & N/A \\
\hline & {$[58]$} & $\mathrm{CB}$ & $12,103-20,051$ & $64,489-130,424$ & $5-500$ & $0.05-20 \mu \mathrm{m}$ & N/A \\
\hline \multirow{7}{*}{ 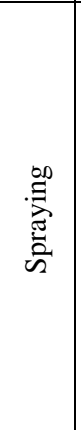 } & {$[6]$} & Silica-iron & $13,300-20,300$ & 79,700 & $10-1000$ & $200-1000 \mathrm{~nm}$ & A. \\
\hline & {$[6]$} & $\mathrm{TiO}_{2}$ & 33,500 & 144,800 & $10-1000$ & N/A & N/A \\
\hline & [9] & ITO, $\mathrm{ZnO}$ & 13,020 & $\begin{array}{c}566,857-8,351,915 \\
(\mathrm{PBZ} 18,000,000)\end{array}$ & $14-673$ & $54 / 99 \mathrm{~nm}$ & N/A \\
\hline & [9] & ITO, $\mathrm{ZnO}$ & 13,020 & $225,000-413,000$ & $14-673$ & $<1 \mu \mathrm{m}, 1-2 \mu \mathrm{m}$ & A. \\
\hline & {$[50]$} & $\mathrm{CeO}_{2}$ & $4,200-27,000$ & $16,000-980,000$ & $10-1100$ & $\begin{array}{c}<10 / 51 / 171 / 454 \\
\mathrm{~nm}\end{array}$ & N/A \\
\hline & {$[58]$} & $\mathrm{SiO}_{2}$ & $19,404-51,348$ & $382,976-1,789,544$ & $10-300$ & $0.5-5 \mathrm{~m}$ & A. \\
\hline & {$[58]$} & $\mathrm{SiO}_{2}$ & $9,909-14,200$ & $121,132-201,383$ & $10-300$ & $0.1-25 \mathrm{~m}$ & A./I. \\
\hline
\end{tabular}




\begin{tabular}{|c|c|c|c|c|c|c|c|}
\hline & Ref & Material & Background, $\mathrm{p} / \mathrm{cm} 3$ & $\begin{array}{l}\text { During activity, } \\
\text { p/cm } 3\end{array}$ & $\begin{array}{l}\text { Sampling size } \\
\text { range, } \mathrm{nm}\end{array}$ & Mean size ${ }^{* *}$ & A. $*$ \\
\hline \multirow{16}{*}{ 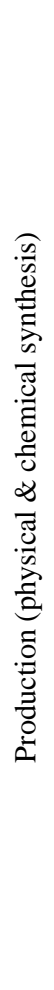 } & [31] & $\mathrm{TiO}_{2}$ & $7,000-20,000$ & 21,000 & $5 \mathrm{~nm}$ to $>32 \mu \mathrm{m}$ & $0.5-1 \mu \mathrm{m}$ & A. \\
\hline & [31] & Specific ENMs & $5,500-15,000$ & $62,000(477,000)$ & $5 \mathrm{~nm}$ to $>32 \mu \mathrm{m}$ & $2 \mu \mathrm{m}$ & A. \\
\hline & {$[67]$} & $\mathrm{TiO}_{2}$ & 11,418 & 45,889 & $15-711$ & $\begin{array}{c}<30 \mathrm{~nm}, 70-100 \\
\mathrm{~nm}\end{array}$ & A. \\
\hline & {$[6]$} & Carbon nanofiber & 13,600 & $59,000-279,700$ & $10-1000$ & $0.1 \times 5 \mu \mathrm{m}$ & A. \\
\hline & {$[6]$} & MWCNT & 6,600 & 42,400 & $10-1000$ & N/A & N/A \\
\hline & {$[6]$} & Metals/metal oxides & $12,000-14,000$ & 85,900 & $10-1000$ & N/A & N/A \\
\hline & {$[6]$} & $\mathrm{Al}$ & 37,700 & 548,500 & $10-1000$ & N/A & N/A \\
\hline & [29] & Metals & 8,512 & $59,100(136,000)$ & $20-673$ & $160-200 \mathrm{~nm}$ & N/A \\
\hline & {$[57]$} & Metals/metal oxides & 2,109 & $\begin{array}{c}\text { Peaks: } 35,494- \\
102,708\end{array}$ & $20-673$ & $112-188 \mathrm{~nm}$ & N/A \\
\hline & {$[72]$} & $\mathrm{Ag}$ & $(4.63-7.9) \mathrm{e}+6$ & $(6.54-18.92) \mathrm{e}+6$ & $15-700$ & $34.6-76.4 \mathrm{~nm}$ & A. \\
\hline & {$[37]$} & CNT/catalyst & N/A & $\begin{array}{l}5,840-37,350 \\
\quad(75,000)\end{array}$ & $5 / 14-500$ & $20-50 \mathrm{~nm}$ & A. \\
\hline & {$[68]$} & CNT & $<2,000$ & $\begin{array}{c}<2,000(\mathrm{PBZ}),(4- \\
10) \mathrm{e}+6\end{array}$ & $5 \mathrm{~nm}-20 \mu \mathrm{m}$ & $\begin{array}{c}7-90 \mathrm{~nm}, 20-200 \\
\mathrm{~nm}\end{array}$ & A. \\
\hline & [39] & $\mathrm{CNF}$ & N/A & N/A & & $0.2-5 \mu \mathrm{m}$ & A. \\
\hline & [76] & Lithium titanium & 15,000 & $20,000-30,000(\mathrm{AM})$ & $10 \mathrm{~nm}-20 \mu \mathrm{m}$ & $\begin{array}{l}>200 \mathrm{~nm}, \text { a few } \\
\text { micrometers }\end{array}$ & A. \\
\hline & [47] & MWCNT & N/A & $500-34,000$ & $10-300$ & $59-65 \mathrm{~nm}$ & N/A \\
\hline & {$[33]$} & silver & $877,364.9$ & $224,622-2,328,608$ & $15-711$ & $<100 \mathrm{~nm}$ & A. \\
\hline \multirow{9}{*}{ 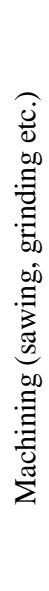 } & {$[45]$} & Carbon fiber & 4,820 & 94,000 & $5.6-560$ & $165 \mathrm{~nm}$ & N/A \\
\hline & {$[45]$} & $\mathrm{CNT} /$ carbon fiber & 4,820 & $\begin{array}{c}153,000 \text { (PBZ), } \\
294,000\end{array}$ & $5.6-560$ & $\begin{array}{c}12 \mathrm{~nm}, 20 \mathrm{~nm}, 230 \\
\mathrm{~nm}, 1 \mu \mathrm{m}\end{array}$ & A. \\
\hline & [45] & Carbon fiber & 4,820 & $\begin{array}{c}319,000 \text { (PBZ), } \\
283,000\end{array}$ & $5.6-560$ & $\begin{array}{c}12 \mathrm{~nm}, \underset{\mathrm{nm}}{20 \mathrm{~nm}, 230} \\
\text {. }\end{array}$ & A. \\
\hline & {$[45]$} & $\begin{array}{l}\text { MWCNT, alumina } \\
\text { fiber }\end{array}$ & 4,820 & 28,000 (PBZ), 38,000 & $5.6-560$ & $\begin{array}{c}12 \mathrm{~nm}, 25 \mathrm{~nm}, 1-4 \\
\mu \mathrm{m}\end{array}$ & A. \\
\hline & {$[45]$} & Alumina fibers & 4,820 & $\begin{array}{c}88,000(\mathrm{PBZ}), \\
148,000\end{array}$ & $5.6-560$ & $\begin{array}{c}12 \mathrm{~nm}, 30 \mathrm{~nm}, 1-2 \\
\mu \mathrm{m}\end{array}$ & A. \\
\hline & [41] & Carbon nanofiber & $10,000-20,000$ & $10,000-20,000$ & $10-1000$ & $400 \mathrm{~nm}$ & A. \\
\hline & [47] & Graphite & N/A & Up to 34,000 & $10-300$ & $30-40 \mathrm{~nm}$ & N/A \\
\hline & [71] & CNT/polymer & 1,000 & 3,000 & $5-1000$ & $<50 \mathrm{~nm},<1 \mu \mathrm{m}$ & A. \\
\hline & {$[44]$} & CNT/polymer & BG corrected & $4,500-430,000$ & $6-560$ & $<10 \mathrm{~nm}, 150 \mathrm{~nm}$ & A. \\
\hline \multirow{4}{*}{$\begin{array}{l}\stackrel{\infty}{\Xi} \\
\stackrel{\Xi}{\Xi} \\
\end{array}$} & {$[6]$} & Oxides(Ag,Mn,Co) & N/A & $62,000-74,000$ & $500-1000$ & $0.5-1 \mathrm{~m}$ & A. \\
\hline & {$[62]$} & $\mathrm{Ag}, \mathrm{Mn}, \mathrm{Co}$ & 12,146 & $\begin{array}{c}10,556-14,071 / \mathrm{LEV} \\
18,196-29,063\end{array}$ & $10-1000$ & $\begin{array}{c}200 \mathrm{~nm}, 500-1000 \\
\mathrm{~nm}\end{array}$ & A. \\
\hline & {$[61]$} & $\mathrm{Ag}, \mathrm{Cu}, \mathrm{Ni}, \mathrm{Fe}, \mathrm{Mn}$ & N/A & $\begin{array}{c}1,300-16,000(\mathrm{BG} \\
\text { subtracted })\end{array}$ & $10-1000$ & $0.5-5 \mu \mathrm{m}$ & A. \\
\hline & {$[31]$} & $\mathrm{TiO}_{2}$ & $7,000-20,000$ & 22,000 & $5 \mathrm{~nm}$ to $>32 \mu \mathrm{m}$ & $0.5-1 \mu \mathrm{m}$ & A. \\
\hline
\end{tabular}

*Agglomeration state: A.: agglomerated or aggregated, I.: individual nanoparticles.

**Mean particle size was taken from the mode sizes in number size distributions or estimated from TEM/SEM images.

Table 3 Release characterizations grouped into different activity types 


\subsection{Emission rate calculations}

Very few of the studies reviewed estimated ENM release rates for the processes that they investigated. Nevertheless, a few scenarios were identified where a rough estimation of release rates might be possible because approximate room size and air exchange information had been provided together with the process characteristics and ENM particle concentrations over time. In one laboratory study in which only basic mechanical ventilation was used, the rate of room air change (or air changes per hour, $\mathrm{ACH}$ ) and the room's dimensions were given [60]. In this case, the release rate can be estimated by integrating particle concentrations over time and the volume flow rate of the air in the room. The average particle concentration in the room can be calculated from source or area measurements, taking into account aerosol transport and diffusion mechanisms (e.g., near- and far-field models). In another study, investigating a laboratory synthesis process, the room's ACH was known, and the ENM emission rate was estimated from the average particle concentration using a one-box model assuming homogeneously mixed room air [57]. On the other hand, if natural ventilation is used [22, 32, 48], such as windows and doors, the room's ACH can be estimated from the ambient environmental conditions (e.g., wind speed, open surface area) assuming normal conditions as described in technical manuals, such as the EPA Exposure Factors Handbook (EPA 2011) or other literature $[77,78]$.

\subsection{Measurement strategy}

The selected studies were also analyzed with regard to the types of measurement devices used, their detection limits, and the size range they could give information about for specific scenarios. Scanning mobility particle sizers (SMPS) were the most frequently used equipment for measuring particle numbers and size distributions below $1 \mu \mathrm{m}$. A Nano-SMPS is sometimes used to obtain more information about the sizes below $100 \mathrm{~nm}$ [25]. Other frequently used devices were: the fast mobility particle sizer (FMPS), which was found to be particularly useful in environments with rapidly changing particle concentrations [22, 45]; optical devices such as the aerodynamic particle sizer (APS, size range up to $32 \mu \mathrm{m}$ ) were used for micro-sized particles [20, 31]; and filters were often used to collect airborne samples in order to assess mass concentrations gravimetrically [6, 36, 64]. A few studies also assessed the surface area of particles [19, 45, 70]. Morphological and elemental analyses were mostly done using electron microscopes $[6,38,54,69]$.

Sampling locations were assessed in order to understand whether source or near-field measurements had been carried out and whether personal breathing zone concentrations - which could provide information about particle transmission from sources to receptors - had been measured. The review showed that source sampling had normally been conducted as close as possible to the potential emission points. For handling nanopowders under fume hoods, the distance was in the centimeter range [9, 14]. For flame and flame-spray production, the measurement position was in several tens of centimeters range or at the nearest opening $[19,34,50,62]$. For largescale manufacturing and processing activities, typical sampling locations were a few meters away from the suspected emission sources $[6,20,21,32,36,63]$. Personal exposure characterization was usually conducted near workers [25, 31], sometimes even next to their noses [14], whereas others measured working positions near the assumed breathing zone of sitting or standing workers $[29,34,38,51,57]$. Filter samplers were mostly clipped to workers' collars, and personal nephelometers were attached to their belts [64]. Area sampling was used either as a background reference or to estimate the general exposure levels in working areas. Background reference levels were collected in production areas away from the immediate vicinity of the processes $[6,7,14,34,38]$, or even outdoors [39]. In order to monitor air quality in normal working areas, near field $(2.5 \mathrm{~m})$ and far field $(7.8 \mathrm{~m})$ concentrations were measured [57]. Maintenance areas and conference rooms were sometimes monitored as well [39].

\subsection{ENM production capacities and quantities handled}

The quantities of ENMs being handled varied from a few milligrams to many tons per year. Table 2 gives an overview on the quantities involved in nanomaterial production and handling in research laboratories and in industry. The production of metals and metal oxides in research laboratories was mostly in the range of grams to kilograms. 
For carbonaceous materials (CNTs, carbon nanofibers, carbon nanopearls), production was often limited to just a few milligrams. In contrast, mass production by industrial manufacturers often ranged from kilograms per batch to tons per year. In research environments, the amounts of materials handled were also significantly lower than those in large-scale production facilities. The quantities treated were usually in the milligram range for activities such as weighing [6] and sonication [7]. For common materials, e.g., alumina powder, up to hundreds of grams could be handled for different purposes [14]. In industrial settings, normal handling activities such as end-product collection, packaging, and bagging of materials were in the same ranges as those seen for the manufacture of these nanomaterials. The largest quantities of novel nanomaterials were reported for titanium dioxide powders, which were processed in kilograms per minutes [24] and bagged in 25-800 kg batches [22]. Traditional materials subject to huge demand, such as $\mathrm{CaCO}_{3}$ and carbon black, could be handled in quantities as much as 60 tons per day [21].

\begin{tabular}{|c|c|c|c|c|c|c|c|}
\hline \multicolumn{2}{|c|}{ Production (laboratory) } & \multicolumn{2}{|c|}{ Production (industry) } & \multicolumn{2}{|c|}{$\begin{array}{l}\text { Handling (laboratory)- } \\
\text { weighing/mixing/sonication }\end{array}$} & \multicolumn{2}{|c|}{$\begin{array}{l}\text { Handling (industry) —collecting, } \\
\text { spraying, mixing, bagging }\end{array}$} \\
\hline Material & Quantity & Material & Quantity & Material & Quantity & Material & Quantity \\
\hline $\mathrm{TiO}_{2}$ & $20 \mathrm{~g} / \mathrm{b}[67]$ & Silicon & $\mathrm{kg} / \mathrm{d}[19]$ & Alumina & 15/100g [14] & $\mathrm{TiO}_{2}$ & 1 kg/min [24] \\
\hline M. oxides & $6 \mathrm{~g} / \mathrm{d}[57]$ & $\mathrm{TiO}_{2}$ & $5-10$ kg/b [6] & $\mathrm{TiO}_{2}, \mathrm{CuO}, \mathrm{Ag}$ & $\mathrm{mg} / \mathrm{b}[6]$ & $\mathrm{TiO}_{2}$ & $25 \mathrm{~kg} / 800 \mathrm{~kg}$ bag [22] \\
\hline Selenide & $\mathrm{g} / \mathrm{b}[6]$ & $\mathrm{Mn} / \mathrm{Ag} / \mathrm{Co} / \mathrm{Fe}$ & $\mathrm{kg} / \mathrm{b}[62]$ & Full./MWCNT & $4-200 \mathrm{mg}[6]$ & $\mathrm{CaCO}_{3}$ & 22.5 ton/d [21] \\
\hline $\mathrm{Al}$ & $\mathrm{kg} / \mathrm{b}[6]$ & Catalysts & $1 \mathrm{~kg} / \mathrm{d}[62]$ & CNT & 4-200 mg [7] & Silica-iron & $\mathrm{kg} / \mathrm{b}[6]$ \\
\hline $\mathrm{Ag}$ & $1-5 \mathrm{~kg} / \mathrm{d}[32]$ & Metal oxides & $1 \mathrm{~kg} / \mathrm{d}[61]$ & CNM & 100 mg/L [7] & $\mathrm{SiO}_{2}$ & 40 kg/600 kg/b [21] \\
\hline MWCNT & $1-2 \mathrm{mg} / \mathrm{b}[6]$ & $\mathrm{Ag}$ & 1200 kg/b [73] & Nanodiamonds & $2 \mathrm{~kg} / \mathrm{d}[27]$ & Fullerene & 40 ton/y [63] \\
\hline $\mathrm{CBF}$ & 500 mg/b [6] & $\mathrm{Ag}$ & $5 \mathrm{~kg} / \mathrm{d}[33]$ & CNTs & $\begin{array}{l}100 \mathrm{~cm}^{3} / \mathrm{s} \\
{[40]}\end{array}$ & MWCNT & $5 \mathrm{~kg} / \mathrm{d}[42]$ \\
\hline \multirow[t]{5}{*}{ CBNPs* } & $200 \mathrm{mg} / \mathrm{b} .[6]$ & SWCNT film & $10,000 / y[55]$ & MWCNT & $<500 \mathrm{~g} / \mathrm{s}[52]$ & CNF & $7 \mathrm{~kg} / \mathrm{bag}[48]$ \\
\hline & & MWCNT & $>100$ kg/d [52] & & & $\mathrm{CB}$ & 60 ton/d [21] \\
\hline & & $\mathrm{CBF}$ & $10-20 \mathrm{~kg} / \mathrm{s}[6]$ & & & & \\
\hline & & CNF & 14.1 ton/y [39] & & & & \\
\hline & & Silica aerogel & 0.5 ton/y [37] & & & & \\
\hline
\end{tabular}

*CBF, carbon nanofiber; CBNPs; carbon nanopearls; Full.: fullerenes; CNMs, carbon based nanomaterials; b, batch; s, shift; $d$, day; m, month; y, year

Table 4. Information on ENM production capacities and amounts handled, from the literature

3.8 Ventilation and personal protective equipment (PPE)

Engineering control systems and PPE play important roles in preventing or reducing personal exposure to hazardous substances in workplaces. The engineering controls described in the reviewed literature can be broadly grouped into four categories:
a. Laboratory fume hoods
b. Local exhaust ventilation (LEV) systems
c. Process-specific enclosures
d. General/centralized ventilation and natural ventilation

Typical PPE includes laboratory clothes, a full-body protection suit, glasses, gloves, and a mask.

Laboratory fume hoods were commonly used when handling small quantities of potentially hazardous materials for activities such as weighing, mixing, transferring [41], sonication [37], and creating solutions [6]. They were also used for experimental-scale physical [34] and chemical synthesis [14, 32, 38, 57]. The design and use of laboratory hoods greatly influences their effectiveness at removing released particles: constant velocity hoods were found to work best during the pouring and transferring of nanopowders, followed by bypass (compensating) hoods, and then conventional hood [14]. 
LEV systems were often employed in industrial environments for controlling particle concentrations at their sources, such as furnaces [64], bagging machines, production lines [9], and during reactor cleanout processes [62]. The efficiency of LEV has been described. While cleaning up after a gas phase condensation of silver, particle release in the $500-1000 \mathrm{~nm}$ size range increased by five times. When a LEV system was used, the particle concentration fell to the background level [6]. During another cleaning process involving nanoscale metal catalytic materials, a properly maintained LEV system was shown to reduce particle mass concentration by $75 \%$ to $96 \%$ (mean: $88 \%$ ), with a similar efficiency for number concentrations [62].

Enclosures of both small and large volumes were seen in fixed installations. These included a ventilated chamber for the electrospinning deposition of nanofibers [6], a positive-pressure glove box during the synthesis and manipulation of quantum dots [6], and a ventilated chamber for spraying a solution, followed by fiberization of absorbent material [6]. Distinct differences in particle concentrations were observed inside and outside such enclosures. One aerosol enclosure chamber significantly reduced particle concentrations during the collection of end products using an industrial cyclone [24]. Enclosing and ventilating the furnace during the production of multi-walled carbon nanotubes (MWCNTs) using chemical vapor deposition (CVD), minimized workers' exposure down to nondetectable levels [36]. In a spraying process, particle emission was shown to be much lower outside the spray enclosure than inside [6]. During flame spraying, average particle number and mass concentrations were 6-46 and 5 times lower, respectively, when a protective enclosure was installed [50]. Discussions on the efficiency of engineering controls can also be found in other studies [23, 35, 36, 67].

Centralized mechanical ventilation and natural ventilation have both been used in large-volume workplaces-such as warehouses and manufacturing areas-in order to help reduce particle concentrations. Rooftop exhaust fans were often seen above production lines [62] where large-scale processing activities such as drying [6], milling, spraying and blending [36], bagging, and packaging [19, 63] were taking place.

PPE was commonly used during material synthesis [62] and handling [37], cleaning, and the mechanical treatment of nanocomposites [6]. The equipment types included gloves, wrist-to-elbow cotton arm covers, full-body Tyvek suits, and full-face positive-pressure airline respirators [62], skin protection, half masks [37], shoe covers, and particulate respirators [6]. In a study of how well 3M FFP2/FFP3 and dräger 680 (FFP3) masks filtered $200 \mathrm{~nm}$ metal-based nanoparticles resulting from gas-phase production, they retained between $96.66 \%$ (FFP2) and 99.99\% (dräger) of the number concentration of particles, respectively, under production conditions [29].

\section{Limitations of the literature to date and suggestions for improvements}

This review found that ENM release characteristics could be grouped by activity type. Process characteristics, such as energy input and system parameters, influenced release levels. The information derived from this analysis provides a good qualitative understanding of the release mechanisms from different activities and processes. However, quantitative determinations of release and exposure remain difficult to achieve. This could be significantly improved by collecting and providing sufficient contextual information.

The literature reviewed in this study contained various types of ENMs in both industrial and laboratory settings. This enabled us to establish a preliminary ranking for nanoparticle release potentials, which could, for example, be used to define priorities for ENM release and occupational exposure assessments. It could also become a guide for the definition of precautionary measures. In our review, release levels and characteristics were comparable within the different types of defined groups of processes; they seemed to be linked to the energy levels associated. Understanding the relationships between specific process parameters and release levels—such as system setups, reaction temperatures, environmental humidity, and material properties-could help to prevent significant releases through safe-by-design approaches. Morphological analyses showed that most of the ENM particles released were in an agglomerated state, which is important to bear in mind for an understanding of their potential impacts on human 
health. However, it is possible that these agglomerates are later broken up into smaller or primary nanoparticles. Studies have shown a possibility for the deagglomeration for nanoparticle agglomerates in the human respiratory system [79, 80], or when the particles are subject to external forces [81-83]. Therefore, in the future, information about the stability of nanoparticle agglomerates may be needed, together with the size information, when characterizing human exposure to ENMs and the risks associated.

Most of the studies assessed focused on the characterization of the released particles' properties close to their source. Only a few of them also provided relevant contextual information for estimating short-term and long-term personal exposure. Missing information often included the properties and amounts of raw materials handled; this would provide information about the material's dustiness and the maximum possible release levels in subsequent exposure estimations. Furthermore, there was little information available that would allow estimations of exposure duration and frequency (e.g., hours/day, days/month, months/year)—data needed to estimate the total exposure dose and its effects of accumulating exposure over the long run. Unfortunately, information useful for an understanding of release was often missing. For example, information on the volume of the workplace, which provides the basis for simulating the potential distribution behavior of released aerosol particles. The same information would permit an estimation of exposure levels in general working areas, which are not often measured. Encouragingly, literature published in recent years seem to start filling these gaps. Clark et al. [2] made a detailed discussion of the limitations of data reporting in exposure assessments and gave recommendations for future methodological improvements. We also recommend that release studies include the collection of exposure-relevant data so that they can have an even better impact and contribution to our understanding of exposure to airborne ENMs.

One significant limitation of the literature to date on airborne ENM release is that it has rarely provided either particle release rates or the contextual data that would allow an estimation of those rates. Most studies only provided near-source concentrations together with sampling distances. Few provided proxies for the near-field flow rate, such as the ventilation rates of local exhaust controls. Thus, the particle concentrations reported in this review are merely indicative of the release potential of the various processes analyzed: they cannot be interpreted mechanistically as actual release levels. Use of a harmonized data collection strategy in future studies may facilitate the assessment of the real release rates of the processes concerned. There is also an opportunity to develop better data collection methods in measurement campaigns. For example, personal exposure levels (breathing zone) could be assessed, as recent studies attempt to inform more frequently on this parameter. This information would allow a validation of models that estimate workers' exposure doses from the source concentration and include physical and contextual parameters. Only a few studies have included data collection that has improved our understanding of particle transmission and dispersion in real world situations, although this would be useful for constructing particle distribution maps.

Another important limitation-one that is relevant to regulators and risk managers-is that the literature reviewed mainly covered the production and use phases of ENM lifecycles. So far there was limited information available on the end-of-life treatment of ENMs. However, these release and exposure scenarios are also important for making an overall risk assessment of ENMs. More recently published studies have started to address this data gap. For example, Massari et al. [84] looked at the behavior of $\mathrm{TiO}_{2}$ nanoparticles during the incineration of solid paint waste. Walser et al. studied the behavior of $\mathrm{CeO}_{2}$ nanoparticles during waste incineration [85, 86]. Gottschalk et al. modeled CNTs release during waste incineration [87, 88]. Reijnders discussed safety issues during the recycling of materials containing persistent inorganic and carbon nanoparticles [89]. Vejerano et al. studied the fate of different nanomaterials during incineration and its effects on the properties of the released particles [90]. Several studies investigated the combustion products of nano-enabled composites [91-93]. Such information allows the current gaps in knowledge to be filled and will complete the data needed for doing risk assessments of ENMs throughout their lifecycles.

A preliminary ranking of the release potential for airborne ENMs could be used to develop a tiered approach to release assessment, resembling the concern-driven approaches used in exposure, hazard, and risk assessments [94]. 
The first step would be a qualitative assessment of the concern levels for specific processes from read-across, by assessing the possibilities for significant exposure and hazard. The second step could then be a quantitative evaluation (e.g., concentration, size, or chemical composition) of field measurements or laboratory simulations. The third step could be a systematic and comprehensive characterization of airborne ENM release scenarios from a process, using different conditions and parameters. This approach would allow the identification of the most critical or at-risk occupational activities in a cost-effective manner.

\section{Acknowledgement}

The research leading to these results has received funding from the European Research Council under the European Union's Seventh Framework Programme (FP/2007-2013) / ERC Grant Agreement n.263215.

\section{Reference}

1. Schmid, K., B. Danuser, and M. Riediker, Nanoparticle usage and protection measures in the manufacturing industry--a representative survey. J Occup Environ Hyg, 2010. 7(4): p. 224-32.

2. Clark, K., et al., Limitations and information needs for engineered nanomaterial-specific exposure estimation and scenarios: recommendations for improved reporting practices. Journal of Nanoparticle Research, 2012. 14(9): p. 1-14.

3. Regulation (EC) No 1907/2006 of the European Parliament and of the Council. Official Journal of the European Union, 18 December 2006.

4. Scientific report: Workplace exposure to nanoparticles. European Agency for Safety and Health at Work (EU-OSHA).

5. Levin, M., et al., Influence of relative humidity and physical load during storage on dustiness of inorganic nanomaterials: implications for testing and risk assessment. Journal of Nanoparticle Research, 2015. 17(8): p. 1-13.

6. Methner, M., et al., Nanoparticle Emission Assessment Technique (NEAT) for the Identification and Measurement of Potential Inhalation Exposure to Engineered Nanomaterials-Part B: Results from 12 Field Studies. J Occup Environ Hyg, 2010. 7(3): p. 163-176.

7. Johnson, D.R., et al., Potential for Occupational Exposure to Engineered Carbon-Based Nanomaterials in Environmental Laboratory Studies. Environmental Health Perspectives, 2010. 118(1): p. 49-54.

8. Imhof, C., et al., Research and development-where people are exposed to nanomaterials. J Occup Health, 2015. 57(2): p. 179-88.

9. Möhlmann, C., et al., Workplace exposure at nanomaterial production processes. Journal of Physics: Conference Series, 2009. 170(1): p. 012004.

10. Bello, D., et al., Characterization of exposures to nanoscale particles and fibers during solid core drilling of hybrid CNT advanced composites. Int J Occup Environ Health, 2010. 16: p. 434 - 450.

11. Gomez, V., et al., Comparison of dust release from epoxy and paint nanocomposites and conventional products during sanding and sawing. Ann Occup Hyg, 2014. 58(8): p. 983-94.

12. Koponen, I., K. Jensen, and T. Schneider, Comparison of dust released from sanding conventional and nanoparticle-doped wall and wood coatings. J Expo Sci Env Epid, 2010: p. 1 - 10.

13. Wohlleben, W., et al., Elastic CNT-polyurethane nanocomposite: synthesis, performance and assessment of fragments released during use. Nanoscale, 2013. 5(1): p. 369-380. 
14. Tsai, S.J., et al., Airborne nanoparticle exposures associated with the manual handling of nanoalumina and nanosilver in fume hoods. Journal of Nanoparticle Research, 2009. 11(1): p. 147-161.

15. Brouwer, D., Exposure to manufactured nanoparticles in different workplaces. Toxicology, 2010. 269(2-3): p. 120-127.

16. ISO/TR 27628:2007, Workplace atmospheres - Ultrafine nanoparticle and nano-structured aerosols - Inhalation exposure characterization and assessment. 2007, ISO.

17. report, N.F., Development of Exposure Scenarios for Manufactured Nanomaterials. 2010.

18. R-Nano.fr-Declaration of Nanomaterials. Available from: https://www.r-nano.fr/.

19. Wang, J., et al., Emission measurement and safety assessment for the production process of silicon nanoparticles in a pilot-scale facility. Journal of Nanoparticle Research, 2012. 14(4).

20. Kuhlbusch, T.A.J., S. Neumann, and H. Fissan, Number size distribution, mass concentration, and particle composition of PM1, PM2.5, and PM10 in bag filling areas of carbon black production. J Occup Environ Hyg, 2004. 1(10): p. 660-671.

21. Tsai, C.J., et al., Exposure assessment of nano-sized and respirable particles at different workplaces. Journal of Nanoparticle Research, 2011. 13(9): p. 4161-4172.

22. Huang, C.H., et al., Measurements of respirable dust and nanoparticle concentrations in a titanium dioxide pigment production factory. Journal of Environmental Science and Health Part a-Toxic/Hazardous Substances \& Environmental Engineering, 2010. 45(10): p. 1227-1233.

23. Kuhlbusch, T.A. and H. Fissan, Particle characteristics in the reactor and pelletizing areas of carbon black production. J Occup Environ Hyg, 2006. 3(10): p. 558-67.

24. Yang, Y., et al., Distribution of Nanoparticle Number Concentrations at a Nano-TiO2 Plant. Aerosol and Air Quality Research, 2012. 12(5): p. 934-940.

25. Maynard, A.D., et al., Exposure to carbon nanotube material: Aerosol release during the handling of unrefined single-walled carbon nanotube material. Journal of Toxicology and Environmental Health-Part A, 2004. 67(1): p. 87-107.

26. Bello, D., et al., Particle exposure levels during CVD growth and subsequent handling of vertically-aligned carbon nanotube films. Carbon, 2008. 46(6): p. 974-977.

27. Koivisto, A., et al., Range-Finding Risk Assessment of Inhalation Exposure to Nanodiamonds in a Laboratory Environment. International Journal of Environmental Research and Public Health, 2014. 11(5): p. 5382.

28. Hedmer, M., et al., Detection of Multi-walled Carbon Nanotubes and Carbon Nanodiscs on Workplace Surfaces at a Small-Scale Producer. Ann Occup Hyg, 2015. 59(7): p. 836-52.

29. Demou, E., P. Peter, and S. Hellweg, Exposure to Manufactured Nanostructured Particles in an Industrial Pilot Plant. Annals of Occupational Hygiene, 2008. 52(8): p. 695-706.

30. Demou, E., W. Stark, and S. Hellweg, Particle emission and exposure during nanoparticle synthesis in research laboratories. Ann Occup Hyg, 2009. 53: p. 829 - 838.

31. Plitzko, S., Workplace exposure to engineered nanoparticles. Inhal Toxicol, 2009. 21 Suppl 1: p. 25-9.

32. Lee, J.H., et al., Exposure assessment of workplaces manufacturing nanosized TiO2 and silver. Inhal Toxicol, 2011. 23(4): p. 226-36.

33. Lee, J.H., et al., Continuous 3-day exposure assessment of workplace manufacturing silver nanoparticles. Journal of Nanoparticle Research, 2012. 14(9): p. 1-10.

34. Yeganeh, B., et al., Characterization of Airborne Particles During Production of Carbonaceous Nanomaterials. Environmental Science \& Technology, 2008. 42(12): p. 4600-4606.

35. Curwin, B. and S. Bertke, Exposure Characterization of Metal Oxide Nanoparticles in the Workplace. J Occup Environ Hyg, 2011. 8(10): p. 580-587. 
36. Han, J.H., et al., Monitoring multiwalled carbon nanotube exposure in carbon nanotube research facility. Inhal Toxicol, 2008. 20(8): p. 741-749.

37. Lee, J.H., et al., Exposure assessment of carbon nanotube manufacturing workplaces. Inhal Toxicol, 2010. 22(5): p. 369-381.

38. Tsai, S.J., et al., Characterization and Evaluation of Nanoparticle Release during the Synthesis of Single-Walled and Multiwalled Carbon Nanotubes by Chemical Vapor Deposition. Environmental Science \& Technology, 2009. 43(15): p. 6017-6023.

39. Birch, M.E., et al., Exposure and Emissions Monitoring during Carbon Nanofiber Production-Part I: Elemental Carbon and Iron-Soot Aerosols. Annals of Occupational Hygiene, 2011. 55(9): p. 10161036.

40. Ogura, I., et al., Release characteristics of single-wall carbon nanotubes during manufacturing and handling. Journal of Physics: Conference Series, 2013. 429(1): p. 012057.

41. Methner, M.M., et al., Identification and characterization of potential sources of worker exposure to carbon nanofibers during polymer composite laboratory operations. J Occup Environ Hyg, 2007. 4(12): p. D125-30.

42. Thompson, D., et al., Aerosol Emission Monitoring and Assessment of Potential Exposure to Multi-walled Carbon Nanotubes in the Manufacture of Polymer Nanocomposites. Annals of Occupational Hygiene, 2015.

43. Fleury, D., et al., Identification of the main exposure scenarios in the production of CNT-polymer nanocomposites by melt-moulding process. Journal of Cleaner Production, 2013. 53: p. 22-36.

44. Boonruksa, P., et al., Characterization of Potential Exposures to Nanoparticles and Fibers during Manufacturing and Recycling of Carbon Nanotube Reinforced Polypropylene Composites. Ann Occup Hyg, 2016. 60(1): p. 40-55.

45. Bello, D., et al., Exposure to nanoscale particles and fibers during machining of hybrid advanced composites containing carbon nanotubes. Journal of Nanoparticle Research, 2009. 11(1): p. 231249.

46. Elihn, K. and P. Berg, Ultrafine Particle Characteristics in Seven Industrial Plants. Annals of Occupational Hygiene, 2009. 53(5): p. 475-484.

47. Hedmer, M., et al., Exposure and emission measurements during production, purification, and functionalization of arc-discharge-produced multi-walled carbon nanotubes. Ann Occup Hyg, 2014. 58(3): p. 355-79.

48. Evans, D.E., et al., Aerosol Monitoring during Carbon Nanofiber Production: Mobile DirectReading Sampling. Annals of Occupational Hygiene, 2010. 54(5): p. 514-531.

49. Shepard, M.N. and S. Brenner, An Occupational Exposure Assessment for Engineered Nanoparticles Used in Semiconductor Fabrication. Annals of Occupational Hygiene, 2013.

50. Leppanen, M., et al., Exposure to CeO2 nanoparticles during flame spray process. Nanotoxicology, 2012. 6(6): p. 643-651.

51. Wang, Y.F., et al., Using a Modified Electrical Aerosol Detector To Predict Nanoparticle Exposures to Different Regions of the Respiratory Tract for Workers in a Carbon Black Manufacturing Industry. Environmental Science \& Technology, 2010. 44(17): p. 6767-6774.

52. Kuijpers, E., et al., Occupational Exposure to Multi-Walled Carbon Nanotubes During Commercial Production Synthesis and Handling. Annals of Occupational Hygiene, 2015.

53. Brenner, S.A., et al., Occupational Exposure to Airborne Nanomaterials: An Assessment of Worker Exposure to Aerosolized Metal Oxide Nanoparticles in Semiconductor Wastewater Treatment. J Occup Environ Hyg, 2015. 12(7): p. 469-81.

54. Park, J., et al., Characterization of exposure to silver nanoparticles in a manufacturing facility. Journal of Nanoparticle Research, 2009. 11(7): p. 1705-1712. 
55. Fonseca, A.S., et al., Characterization of exposure to carbon nanotubes in an industrial setting. Ann Occup Hyg, 2015. 59(5): p. 586-99.

56. Heitbrink, W.A., L.M. Lo, and K.H. Dunn, Exposure controls for nanomaterials at three manufacturing sites. J Occup Environ Hyg, 2015. 12(1): p. 16-28.

57. Demou, E., W.J. Stark, and S. Hellweg, Particle Emission and Exposure during Nanoparticle Synthesis in Research Laboratories. Annals of Occupational Hygiene, 2009. 53(8): p. 829-838.

58. Bekker, C., et al., Occupational Exposure to Nano-Objects and Their Agglomerates and Aggregates Across Various Life Cycle Stages; A Broad-Scale Exposure Study. Annals of Occupational Hygiene, 2015.

59. Peters, T.M., et al., Airborne Monitoring to Distinguish Engineered Nanomaterials from Incidental Particles for Environmental Health and Safety. J Occup Environ Hyg, 2009. 6(2): p. 7381.

60. Bello, D., et al., Exposure to nanoscale particles and fibers during machining of hybrid advanced composites containing carbon nanotubes. Journal of Nanoparticle Research, 2009. 11(1): p. 231249.

61. Methner, M.M., Effectiveness of a Custom-fitted Flange and Local Exhaust Ventilation (LEV) System in Controlling the Release of Nanoscale Metal Oxide Particulates During Reactor Cleanout Operations. International Journal of Occupational and Environmental Health, 2010. 16(4): p. 475-487.

62. Methner, M.M., Engineering case reports. Effectiveness of local exhaust ventilation (LEV) in controlling engineered nanomaterial emissions during reactor cleanout operations. J Occup Environ Hyg, 2008. 5(6): p. D63-9.

63. Fujitani, Y., et al., Measurement of the physical properties of aerosols in a fullerene factory for inhalation exposure assessment. J Occup Environ Hyg, 2008. 5(6): p. 380-389.

64. Miller, A., et al., Characterizing exposures to airborne metals and nanoparticle emissions in a refinery. Ann Occup Hyg, 2010. 54(5): p. 504-13.

65. Maynard, A., et al., Exposure to carbon nanotube material: Aerosol release during the handling of unrefined single walled carbon nanotube material. J Toxic And Environ Health, 2004. 67: p. 87 - 107.

66. Evans, D., et al., Aerosol monitoring during carbon nanofiber production: Mobile direct-reading sampling. Ann Occup Hyg, 2010. 54(5): p. 514 - 531.

67. Lee, J., et al., Exposure assessment of workplaces manufacturing nanosized TiO2 and silver. Inhal Toxicol, 2011. 23(4): p. 226 - 236.

68. Tsai, S., et al., Characterization and evaluation of nanoparticle release during the synthesis of single-walled and multiwalled carbon nanotubes by chemical vapor deposition. Env Sci Technol, 2009. 43: p. 6017 - 6023.

69. Mazzuckelli, L., et al., Identification and characterization of potential sources of worker exposure to carbon nanofibres during polymer composite laboratory operations. J Occup and Environ Hyg, 2007. 4: p. D125 - D130.

70. Wang, Y., et al., Using a modified electrical aerosol detector to predict nanoparticle exposure to different regions of the respiratory tract for workers in Carbon Black manufacturing industry. Environ Sci Technol, 2010. 44: p. 6767 - 6774.

71. Fleury, D., et al., Identification of the main exposure scenarios in the production of CNT-polymer nanocomposites by melt-moulding process. Journal of Cleaner Production, 2013. 53(0): p. 22-36.

72. Park, J., et al., Characterization of exposure to silver nanoparticles in a manufacturing facility. J Nanopart Res, 2009. 11: p. 1705 - 1712.

73. Miller, A., et al., Characterizing Exposures to Airborne Metals and Nanoparticle Emissions in a Refinery. Annals of Occupational Hygiene, 2010. 54(5): p. 504-513. 
74. Pietroiusti, A. and A. Magrini, Engineered nanoparticles at the workplace: current knowledge about workers' risk. Occup Med (Lond), 2014. 64(5): p. 319-30.

75. Kuhlbusch, T., et al., Nanoparticle exposure at nanotechnology workplaces: A review. Particle and Fibre Toxicology, 2011. 8(1): p. 22.

76. Peters, T., et al., Airborne Monitoring to Distinguish engineered Nanomaterials from Incidental particles for environmental health and safety. J Occup and Environ Hyg, 2009. 6: p. 73 - 81.

77. Hang, J., et al., Natural ventilation assessment in typical open and semi-open urban environments under various wind directions. Building and Environment, 2013. 70(0): p. 318-333.

78. You, Y., et al., Measurement of air exchange rates in different indoor environments using continuous CO2 sensors. Journal of Environmental Sciences, 2012. 24(4): p. 657-664.

79. Li, W.-I., et al., Aerodynamics and aerosol particle deaggregation phenomena in model oralpharyngeal cavities. Journal of Aerosol Science, 1996. 27(8): p. 1269-1286.

80. Li, W.-I. and D.A. Edwards, Aerosol particle transport and deaggregation phenomena in the mouth and throat. Advanced Drug Delivery Reviews, 1997. 26(1): p. 41-49.

81. Stahlmecke, B., et al., Investigation of airborne nanopowder agglomerate stability in an orifice under various differential pressure conditions. J Nanopart Res, 2009. 11(7): p. 1625 - 1635.

82. Ding, $\mathrm{Y}$. and $\mathrm{M}$. Riediker, $A$ system to assess the stability of airborne nanoparticle agglomerates under aerodynamic shear. Journal of Aerosol Science, 2015. 88(0): p. 98-108.

83. Sosnowski, T.R., K. Giżyńska, and Ł. Żywczyk, Fluidization and break-up of powder particle aggregates during constant and pulsating flow in converging nozzles. Colloids and Surfaces A: Physicochemical and Engineering Aspects, 2014. 441(0): p. 905-911.

84. Massari, A., et al., Behavior of TiO2 nanoparticles during incineration of solid paint waste: A labscale test. Waste Management, 2014. 34(10): p. 1897-1907.

85. Walser, T., et al., Persistence of engineered nanoparticles in a municipal solid-waste incineration plant. Nat Nano, 2012. 7(8): p. 520-524.

86. Walser, T. and F. Gottschalk, Stochastic fate analysis of engineered nanoparticles in incineration plants. Journal of Cleaner Production, 2014. 80: p. 241-251.

87. Gottschalk, F., et al., Modeled Environmental Concentrations of Engineered Nanomaterials (TiO2, $\mathrm{ZnO}, \mathrm{Ag}, \mathrm{CNT}$, Fullerenes) for Different Regions. Environmental Science \& Technology, 2009. 43(24): p. 9216-9222.

88. Gottschalk, F., et al., Possibilities and limitations of modeling environmental exposure to engineered nanomaterials by probabilistic material flow analysis. Environmental Toxicology and Chemistry, 2010. 29(5): p. 1036-1048.

89. Reijnders, L., 11 - Safe recycling of materials containing persistent inorganic and carbon nanoparticles, in Health and Environmental Safety of Nanomaterials, J. Njuguna, K. Pielichowski, and H. Zhu, Editors. 2014, Woodhead Publishing. p. 222-250.

90. Vejerano, E.P., et al., Characterization of particle emissions and fate of nanomaterials during incineration. Environmental Science: Nano, 2014. 1(2): p. 133-143.

91. Calogine, D., et al., Gaseous effluents from the combustion of nanocomposites in controlledventilation conditions. Journal of Physics: Conference Series, 2011. 304: p. art 012019.

92. Sotiriou, G.A., et al., Thermal decomposition of nano-enabled thermoplastics: Possible environmental health and safety implications. Journal of Hazardous Materials, 2016. 305: p. 8795.

93. Sotiriou, G.A., et al., An integrated methodology for the assessment of environmental health implications during thermal decomposition of nano-enabled products. Environmental Science: Nano, 2015. 2(3): p. 262-272. 
94. Oomen, A.G., et al., Concern-driven integrated approaches to nanomaterial testing and assessment--report of the NanoSafety Cluster Working Group 10. Nanotoxicology, 2014. 8(3): p. 334-48. 
